\title{
A Practical Design Approach to Improve the Charging Efficiency of a Small Two-Stroke High- Speed Engine Based on Basic CFD
}

\author{
Massimo Masi ${ }^{1, *}$, Matteo Pregrasso ${ }^{2}$, and Paolo Gobbato ${ }^{3}$ \\ ${ }^{1}$ University of Padova, Department of Management and Engineering - DTG, Vicenza, Italy \\ ${ }^{2} \mathrm{SCM}$ Group, Industrial Machinery, Mechanical design engineer, Rimini, Italy \\ ${ }^{3}$ Veil Energy Srl, R\&D Manager - TEG system, Bolzano, Italy
}

\begin{abstract}
The paper deals with the optimisation of the charging efficiency in a small two-stroke high-speed engine according to well-established design guidelines. The aim is to present the method successfully used in the preliminary screening of the performance improvement attainable in a crank-case-compression engine by design modifications to the transfer ports and manifolds. The method applies a basic CFD model of the steady-state flow across the cylinder block validated against experimental tests at the discharge flow bench. This model is used to approximate the actual scavenging process through a transient simulation of the cold flow across the cylinder inside which the piston is fixed at the bottom centre. A fast assessment of the charging efficiency is permitted by a transported passive scalar implemented in the model to easily estimate all the parameters needed for monitoring the effectiveness of the scavenging process at each crankangle. This practical design approach has been applied to the geometry of a Schnürle-type loop-scavenged $125 \mathrm{cc}$ single-cylinder engine compliant with the 2018 FIA homologation form for the KF2 karting competition category. The maximum increase of indicated mean effective pressure expected according to the comparison between the CFD simulations of the original and the modified design of the transfer ports is approximately equal to $4 \%$. This result demonstrates that the CFD analyses are sensitive to the limited modifications commonly needed to tune two-stroke racing-engines and confirms that the suggested design approach can be profitably employed by engineers and technicians involved in the design of small two-stroke highspeed engines.
\end{abstract}

\section{Introduction}

The effectiveness of the gas exchange process is crucial for two-stroke engines where the opening time (in crank angle degrees) of conventional piston-controlled transfer ports for small crankcase-compression engines hardly exceeds $110^{\circ}$ [1]. Accordingly, designers and

\footnotetext{
* Corresponding author: massimo.masi@unipd.it
} 
technicians involved in the field of two-stroke engines still today devote much of their effort on the improvement of cylinder scavenging techniques and concepts $[2,3]$.

The subject of this paper is the optimisation of the charging efficiency in an existing highspeed two-stroke engine for karting competitions and, in particular, the design approach used to improve the geometry of the transfer ports.

An effective gas exchange process is the result of the concurrent optimisation of the following:

- Aerodynamic design of transfer and exhaust ports;

- Inertia and pressure pulsation effects (length, cross-sectional area and volume of manifolds and capacities in the admission and exhaust systems);

- $\quad$ Timing and duration of the cylinder ports opening period.

Accordingly, experimental facilities for transient testing as well as unsteady numerical simulations are the best tools to support the optimisation of the scavenging process.

Transient testing - In the past, transient tests on an optically accessible hydraulic simulacrum of the engine running under motored conditions allowed flow visualisations of the scavenging process simulated by a liquid that scavenges another [4]. Measurements of the chemical composition of the fresh charge and exhaust gas under firing operation of the engine are still widely used today because they permit very accurate measurements of global performance parameters of the scavenging process [5]. The most accurate experimental approach provides high-frequency local velocity data on the real engine during fired or motored operation, through consolidated optical measurements techniques (e.g., particle image or Laser Doppler Velocimetry LDV $[6,7,8])$.

Unsteady numerical simulations - Computational Fluid Dynamics (CFD) relying on Unsteady Reynolds Averaged Navier-Stokes (URANS) multi-cycle simulations on movinggrid domains with topology changes has become a reliable and widely used tool to support the optimisation of two-stroke engines. In particular, satisfactory predictions of the incylinder pressure and exhaust emissions have been recently obtained for uniflow-scavenged large marine compression ignition engines through reactive simulations [9]. Additionally, non-reactive multi-cycle computations [3] and moving-grid analyses of the blow-down to end-of-compression crank angle period [6] demonstrated the capability of quite accurate resolution in space and time of the gas exchange process. Such cold-flow CFD approaches applied to small two-stroke racing engines achieved good reliability in the early 2000s [10, $11]$.

However, neither the numerical analysis expertise and experience in using the commercial CFD tools to setup and manage very complex numerical simulations nor the experimental facilities recalled above are easily accessible to many researchers and manufacturers of small two-stroke racing engines. This evidence justifies the practical design approach proposed here as a rapid and cost-effective method to improve loop-scavenged crankcase-compression engines. This process requires experimental facilities, computational resources and techno-scientific and numerical expertise available in most of engine laboratories and R\&D centres because it relies on basic CFD analyses supported by easily accessible experimental techniques.

Well-established research findings [12] and design guidelines for small two-stroke race engines [13] comprise the technical base of the suggested approach. Local velocity measurements performed at the discharge flow bench for several two-stroke engine designs established the key features of the scavenging flow that minimise the short-circuit of the charge and validated well-known criteria to avoid poor scavenging designs [12]. Although these tests cannot account for any transient effect (piston motion, exhaust blowdown and time dependence of the carter-to-exhaust pressure ratio), more recent studies (e.g., [8, 14]) confirmed these results on motored engines, which show good reliability despite the absence of blow-down and related unsteady effects. According to [7], the charge delivered to the 
cylinder at different engine speeds behaves similarly during fired and motored operations, and the higher the speed, the more accurate the motored tests. This explains why 'steady flow engine tests have been found useful by many engine manufacturers as a first step in engine port geometry design' [1].

This paper presents a practical design approach to improve the charging efficiency of a small two-stroke high-speed engine relying on a steady-flow engine model. To this end, a five-port loop-scavenged race engine compliant with the KF2 FIA homologation was used as baseline design.

The paper is structured as follows. The first section illustrates the conceptual bases, the logical structure and the requirements of the practical design approach. The second section presents the engine under analysis, the experimental apparatus and the CFD model required by the design approach. Finally, the successful application of the design approach is briefly reported in the third section that precedes the final summary.

\section{Practical design approach}

In the following, the experimental and numerical tools and related requirements, the 3 -steps logical structure of the design approach, and the limits of the method are addressed in three distinct sub-sections.

\subsection{Experimental and numerical requirements}

The design approach relies on a steady flow engine CFD model (CFD-C model hereafter) as the performance analysis tool. The CFD-C model simulates the steady flow across the entire cylinder-head assembly with the piston fixed at the bottom centre (BC) to mimic ideal scavenging of the real engine in a typical steady-state test performed at the discharge flow rig [1]. This model does not involve very sophisticated physics or the use of grid motion techniques because it simulates a stationary (i.e., no piston motion) low-speed (i.e. incompressible) flow without sprays, phase changes, chemical reactions and heat exchange. Such CFD simulation, therefore, requires: (i) a basic model that can be easily managed with the base package of a general-purpose CFD software, which does not require considerable computational resources or researchers or engineers extremely specialised in engine CFD, and (ii) an accessible steady-flow rig to perform three different discharge-flow tests and validate the CFD. Two of these tests, A and B hereafter, are those usually performed for crankcase-compression loop-scavenged engines to obtain the discharge flow coefficients (direct-flow) through the transfer and exhaust ports at several piston positions [15]. Both tests are performed without the cylinder head to approximate the in-cylinder flow path occurring in a loop-scavenging process. In test A, the exhaust ports are filled with a plug of modelling clay and the air is sucked across the transfer ducts by flanging the cylinder top to the negative pressure chamber of the rig. In test B, the transfer ports are filled with the modelling clay and the air is sucked from the top of cylinder across the exhaust ports by flanging the exhaust duct end to the negative pressure chamber. These two tests are best suited for separate validations of the two corresponding CFD models, i.e. the transfer ports flow model (CFDA) and the exhaust ports flow model (CFD-B). In the third test, test $C$ hereafter, the air flows across the transfer ports as it is sucked across the primary exhaust duct, which is flanged to the negative pressure chamber as in test $\mathrm{B}$. Thus, test $\mathrm{C}$ is the experimental analogue of the CFD-C model described above and allows validating the model required for the design approach. Once the experimental data from tests A, B and C are available, the setup of the corresponding CFD models (CFD-A, -B and $-\mathrm{C}$, respectively) requires the CAD models of cylinder, transfer, and exhaust manifolds to define the geometrical domains (reverse engineering is necessary, if CAD is not available). 


\subsection{Structure of the practical design approach}

The practical design approach is organised into the following three steps.

Step I - The features of in-cylinder flow as predicted by the steady-state CFD-C model are compared to those required by the most effective loop-scavenge process. According to [12], effective cylinder scavenging, which minimises the short-circuit of the charge, occurs when the zero axial-velocity line halves the cylinder. This means the fresh charge is directed towards the combustion chamber dome and scavenges the back half of the cylinder before turning down and displacing the burnt gas in the front half of the cylinder towards the exhaust. If the simulated flow field exhibits noticeably non-ideal behaviour, an improvement of the scavenging process can be obtained in step II. The distribution of the velocity vectors indicates the most critical zones for the scavenging process and may suggest geometrical modifications to be considered in the next step.

Step II - The design guidelines reported in [1] and [13] should be followed for an effective gas exchange process. For example, the design guidelines in [13] identify the following: the maximum elevation angle and the tangential direction of the transfer ports, and the degree of their radial convergence, the reference values for the intersection points of corresponding ports, the admissible axial inclination range for the booster port facing the exhaust (i.e. the 'coanda'), and so forth. If several geometrical parameters assume values noticeably different from the reference, it is suggested focusing on the most different ones and, among them, on those for which the values can be easily modified without exceeding the allowances in the homologation form or other constraints (if any). Also, multiple geometrical modifications at the same time should be avoided (if not imposed by concurrent constraints) to keep better control of the effectiveness of each modification.

Step III - The geometrical modifications provided by Step II must be included in the CAD model to update the CFD-C model. After a comparative analysis of the new and previous results according to the Jante criterion [12], if the inspection of the in-cylinder flow reveals a noticeable sensitivity to the modification, additional CFD simulations should be performed using the transient calculation mode in the CFD-C models of the original and the modified geometries. These unsteady simulations could also be useful to compare key features of the two design, including vortices and instabilities of the scavenging flow, similar to the old visualisation technique based on indicator strips [16]. However, these CFD simulations are specifically suggested to:

i. Verify the increased effectiveness of the scavenging process by comparing time histories and final values of the most important scavenging parameters reported in Tab.1.

ii. Approximately quantify the indicated power increase from the improved design.

In fact, the engine power $P$ at a given rotational speed $N$ depends on the product of mechanical efficiency $\eta_{m}$, indicted fuel conversion efficiency $\eta_{f, i}$, and total charging efficiency $\eta_{c h}{ }^{\text {tot }}$ as summarised in eq. (1).

$$
P /_{N}=T \approx b m e p=\eta_{m} \text { imep } \approx \eta_{m} \eta_{f, i} \eta_{c h}^{\text {tot }}
$$

where $T$ is the engine torque and bmep and imep are the brake and indicated mean effective pressures, respectively. Thus, if $\eta_{m}$ and $\eta_{f, i}$ are not affected by the modifications, the engine output increases by the ratio of the new $\eta_{c h}^{\text {tot }}$ to that of the baseline. 
Table 1. Scavenging parameters suggested for the Step III (defined in accordance with [1]).

\begin{tabular}{|c|c|c|}
\hline Parameter & General definition & $\begin{array}{c}\text { Final value } \\
\text { (at Transfer/Exhaust Close - @TC/EC) }\end{array}$ \\
\hline $\begin{array}{l}\text { Delivery } \\
\text { ratio }\end{array}$ & $\Lambda=\frac{\text { mass of fresh charge delivered to the cylinder }}{\rho_{0} V_{c y l}}$ & $\begin{array}{l}\Lambda^{\text {tot }} \\
=\frac{\text { mass of fresh charge delivered to the cylinder @TC }}{\rho_{0} V_{c y l}}\end{array}$ \\
\hline $\begin{array}{l}\text { Trapping } \\
\text { efficiency }\end{array}$ & $=\frac{\text { mass of delivered charge retained in the cylinder }}{\text { mass of fresh charge delivered to the cylinder }}$ & $=\frac{\text { mass of delivered charge trapped in the cylinder } @ E C}{\text { mass of fresh charge delivered to the cylinder }}$ \\
\hline $\begin{array}{l}\text { Scavenging } \\
\text { efficiency }\end{array}$ & $=\frac{\text { mass of delivered charge retained in the cylinder }}{\eta_{s c}}$ & \\
\hline $\begin{array}{c}\text { Purity of the } \\
\text { charge }\end{array}$ & $=\frac{\text { fresh charge mass flow at the exhaust port }}{\text { total mass flow at the exhaust port }}$ & \\
\hline $\begin{array}{l}\text { Charging } \\
\text { efficiency }\end{array}$ & $\eta_{c h}=\eta_{r t} \Lambda$ & $\eta_{c h}^{t o t}=\eta_{t r} \Lambda^{t o t}$ \\
\hline
\end{tabular}

\subsection{Limits of the design approach}

The reliability of the design approach formalised above is strongly dependent on the capability of a steady-flow scavenging model (i.e., CFD-C) to describe the actual scavenging process. A steady flow model may appear to not be compatible with the intrinsically timedependent behaviour of the gas exchange process in a two-stroke reciprocating engine. In fact, the LDV data measured on a motored engine [17] confirm that the local direction and magnitude of the velocity at the piston-controlled ports of a loop-scavenged engine depend on the piston position (i.e., on the crank angle). However, the CFD analyses [18] demonstrated a minor effect of the actual velocity distribution at the transfer ports when compared to an idealised uniform distribution (plug flow). Also, the mean velocities measured in [7] at the transfer port of a fired engine at full- and part-throttle operations indicate strong dependence on the piston position. On the other hand, [17] also reported rotation and elevation efflux angles at the transfer port that were roughly constant for half the opening period of the transfer ports around $\mathrm{BC}$, at all engine speeds. Moreover, the fullthrottle and full-speed data set in [7] shows almost steady velocities at the transfer port that fluctuate only slightly for half the crank-angle period in which the transfer ports are open. These findings help validate the CFD-C model in simulating the mid-half of the scavenging process, where the piston is close to $\mathrm{BC}$ and moves with a negligible speed, and specifically when the real engine runs at the design condition. However, for the present design approach, this oversimplified model is able to predict the trends associated with local modifications of a specific engine design, especially when the engine has significant potential for optimisation.

\section{Experimental and numerical tools}

This section is organised in four sub-sections. The first sub-section describes the engine used to test the design approach presented. The second sub-section deals with the experimental setup to measure the discharge-flow coefficients of the engine, whereas the third sub-section presents the basic CFD models built to apply the design approach. Finally, the degree of accuracy of the CFD models is assessed in the fourth sub-section.

\subsection{Engine}

The design approach was applied on a two-stroke XT single-cylinder engine manufactured by Maxter srl - a Schnürle-type loop-scavenged 125cc engine with crankcase compression, 
compliant with the 2018 FIA homologation form for the KF2 karting competition category. Table 2 lists the main technical specifications of the engine as reported in the 30/M/18-KF2 FIA homologation form (to which the reader is referred for additional data).

Table 2. Main features of the Maxter XT two-stroke engine under analysis.

\begin{tabular}{|c|c|c|c|}
\hline $\begin{array}{c}\text { Technical } \\
\text { specification }\end{array}$ & Drive side of the complete \\
engine
\end{tabular}

\subsection{Discharge flow test rig}

Table 3 summarises the main features of the steady-state discharge flow test bench used to measure the steady-state discharge flow coefficients of the transfer and exhaust port of the engine as well as to validate the CFD models.

Table 3. Key features of the discharge flow bench and technical data of the instrumentation.

\begin{tabular}{|c|c|}
\hline \multicolumn{1}{|c|}{ Layout of the test rig } \\
$\begin{array}{c}\text { From left to right: } \\
\text { (1) - engine cylinder; } \\
\text { (2) - plenum chamber; } \\
\text { (3) - orifice plate to measure air } \\
\text { flow rate; } \\
\text { (4) - variable speed fan to fix the } \\
\text { chamber pressure. }\end{array}$ & Instrumentation and technical data \\
\hline Measured data & Water U-manometer -10 Pa reading resolution \\
\hline Cylinder ports pressure drop & Water micro-manometer- 0.1 Pa reading resolution \\
\hline Orifice plate pressure drop & Dial indicator- 0.01 mm reading resolution \\
\hline Piston position & Wet and dry bulb thermometer $-0.5^{\circ} \mathrm{C}$ reading resolution \\
\hline Air humidity & Oregon Scientific ${ }^{\circ}$ BAR208HGX Weather Station -100 Pa res. \\
\hline Ambient pressure
\end{tabular}


The different flow bench setups required to perform the discharge flow tests $\mathrm{A}, \mathrm{B}$ and $\mathrm{C}$ are shown in Fig. 1(f). Figure 1 also shows the series of ancillary components that are needed to perform such tests, i.e. the flanges to connect the pressure chamber to the cylinder (b) and exhaust duct (c), the bell-mouth intake (a) for a smooth flow inlet in test B, the transfer ducts inlet adapter (d) to mimic at the flow bench a smooth flow entrance from the crankcase in tests $\mathrm{A}$ and $\mathrm{C}$, and the adjustable piston support (e) to change the level of ports opening.

All the discharge-flow tests were performed keeping the total-to-static pressure drop constant at the negative pressure chamber of the rig at each piston position. The pressure drop was fixed to obtain a mass flow rate at the maximum opening of the ports equal to $0.05 \mathrm{~kg} / \mathrm{s}$, which is approximately the average mass flow delivered to the actual engine cylinder in operation at $13000 \mathrm{rpm}$.

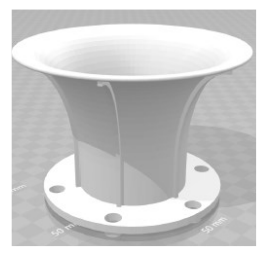

(a)

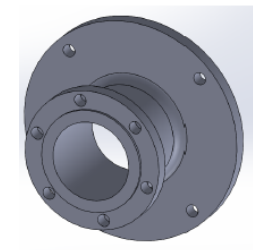

(b)

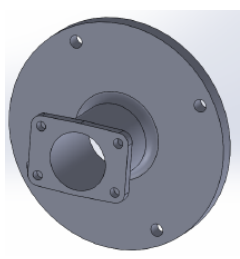

(c)

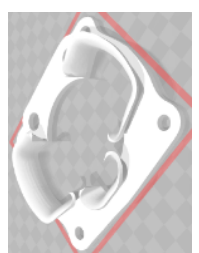

(d)

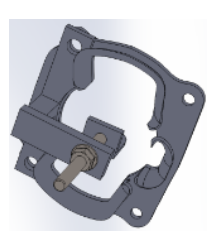

(e)
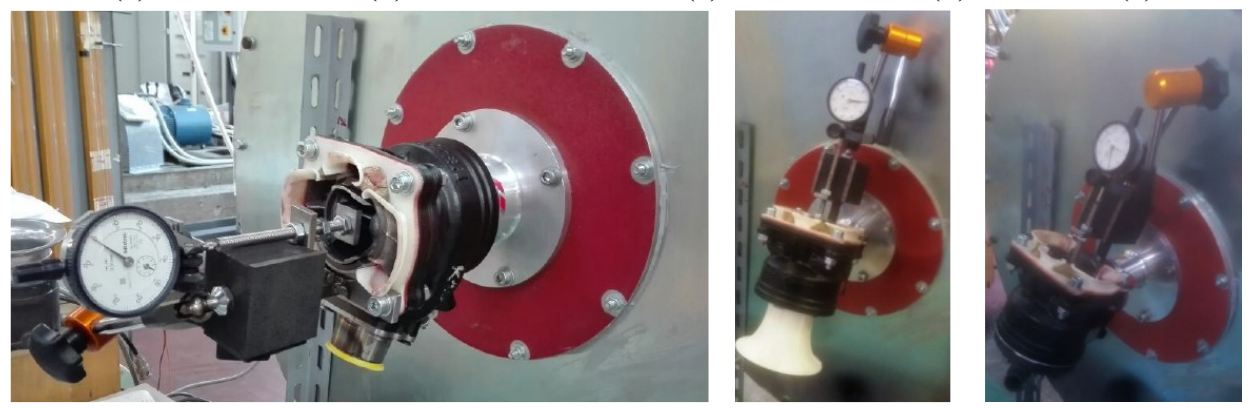

(f)

Fig. 1. Details of the experimental facility: head bell-mouth (a); head (b) and exhaust (c) flanges; transfer ports intake adaptor (d); adjustable piston support (e); setup for tests A (f-left), B (f-middle), and $\mathrm{C}$ (f-left).

The two discharge flow coefficients $C_{d}$ and $C_{f}$, as defined in eq.(2), quantify the mass flow rate data $\dot{m}$ across the ports in dimensionless form as a function of a reference area Aref, equal to either the piston surface for $C_{d}$ or the geometric area of the ports not covered by the skirt at a specific piston position for $C_{f}$.

$$
C_{d}, C_{f}=\frac{\dot{m}}{\rho_{0} A_{r e f} v_{i s}}
$$

where $\rho_{0}$ and $v_{i s}$ are the air mass density and the isentropic speed across the ports, respectively. The latter depends on the upstream total pressure $p_{0}$ (ambient pressure), the pressure in the negative pressure chamber $p_{c}$ and the air specific heat ratio $\gamma$, and it is defined as follows:

$$
v_{i s}=\sqrt{\frac{2 \gamma}{\gamma-1} p_{0} \rho_{0}\left[1-\left(\frac{p_{c}}{p_{0}}\right)^{\frac{\gamma-1}{\gamma}}\right]}
$$


The results of tests $\mathrm{A}, \mathrm{B}$, and $\mathrm{C}$ are reported as discharge coefficient $C_{d}$ (i.e. dimensionless effective area) curves in Figs. 2(b), 2(a), and 2(c), respectively. Each datum is the arithmetic mean of data collected in four repetitions of each test. The coloured zones in the diagrams show the ranges of effective areas uncovered by the piston from $25 \%$ to $75 \%$ of the actual ports opening duration (the right bounds of the coloured zones correspond to the $\mathrm{BC}$ piston position in the actual engine). The results of test $\mathrm{C}$ demonstrate that the effective area available to scavenge the actual cylinder is roughly equal to the maximum opening for half the duration of the transfer port opening period.

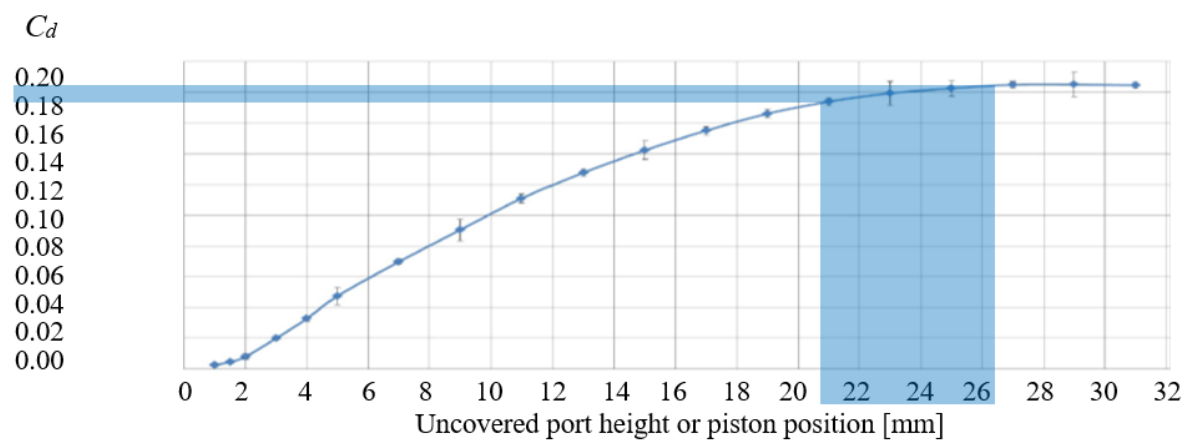

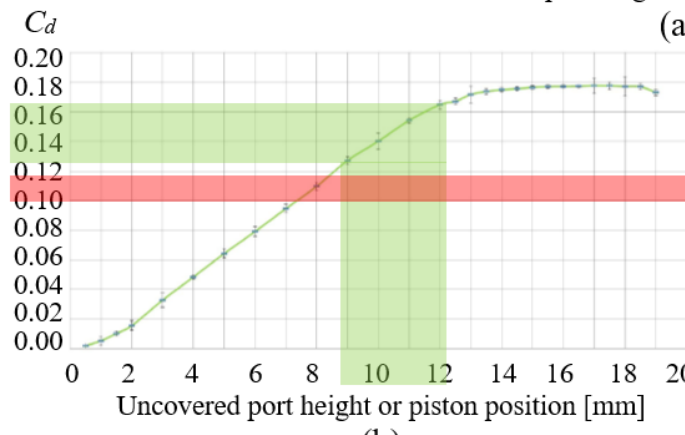

(b) (a)

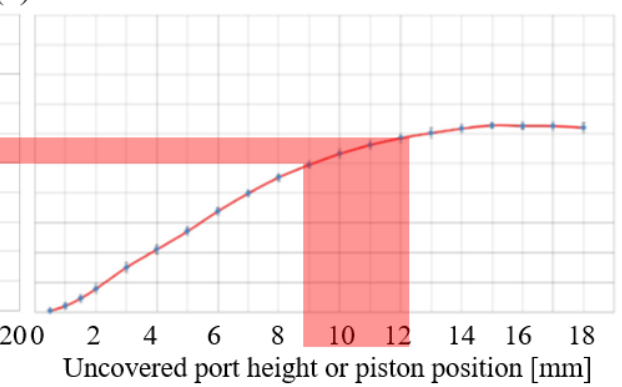

(c)

Fig. 2. Dimensionless effective flow area $C_{d}$ at different piston positions (in abscissae) measured in tests B (a), A (b), and C (c) - error bars show the 95\% confidence level according to the Student distribution, coloured areas show the ranges of effective areas available from $25 \%$ to $75 \%$ of the ports opening duration.

\subsection{Basic CFD model}

Figure 3(a) shows the rubber moulds used to reconstruct the CAD model of the original geometry through the reverse engineering process described in Fig 3(b). Figures 3(c) and 3(d) show the computational domains used in the CFD-A, -B and -C models. Each domain represents half of the corresponding actual geometry. All the domains are bounded by two hemispherical plenums simulating the inlet environment and the pressure chamber of the test rig.

The CFD simulation assumed incompressible flow in the discharge flow tests using the steady-state RANS approach with the Standard $\kappa-\varepsilon$ turbulence closure and the 'high $\mathrm{y}^{+}$wall treatment' implemented in the release 11 of CD-Adapco ${ }^{\circledR}$ Star CCM+ finite volume code.

A total-to-static pressure drop equal to the relative vacuum fixed during the experiments in the pressure chamber of the flow bench was imposed across each domain. All solid surfaces were modelled as no-slip walls, and second-order upwind was chosen to model the 
convective fluxes in the momentum equations. The segregated solver was stopped when the residuals of the momentum and continuity equations fell below $10^{-9}$ and $10^{-7}$, respectively.

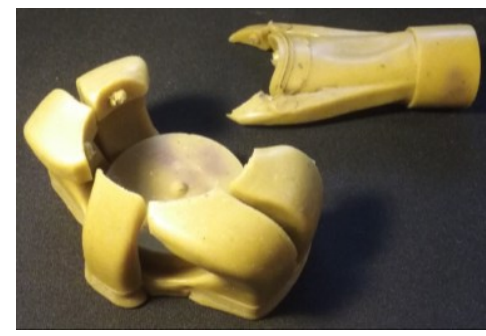

(a)

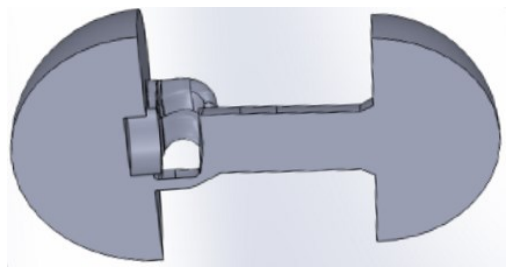

(c)

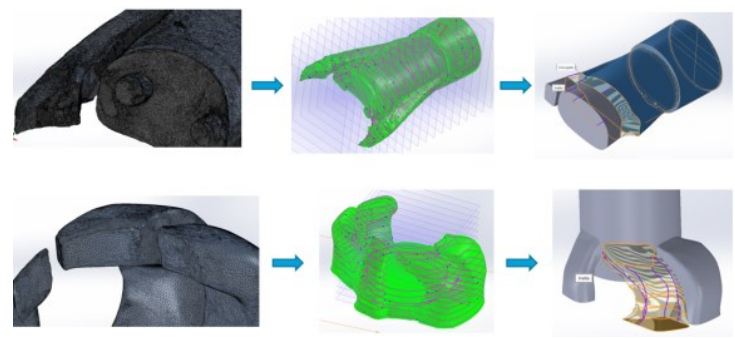

(b)
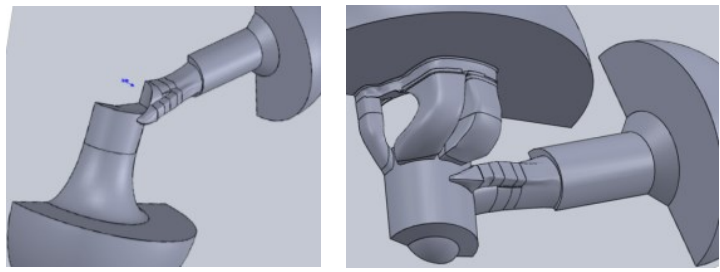

(d)

Fig. 3. Real geometry: rubber moulds of the transfer and exhaust ducts (a); Reverse engineering reconstruction: from ultrafine 3D scan mesh, to geometrical representation, to CAD (b); Geometrical domains (as positioned in Fig.1 pictures) simulated in the CFD-A (c), CFD-B (d-left) and CFD-C (dright) models.

Details of the polyhedral non-structured grids used to discretise the computational domains of CFD-C and-B models are shown in Figs. 4(a) and 4(b), respectively. The cell size progressively decreases in the direction from the hemispherical surfaces towards the cylinder up to a fixed base size, which was kept uniform in the core of the domain far from the wall. All the grids in the three models include a two-cell prism layer near the walls.

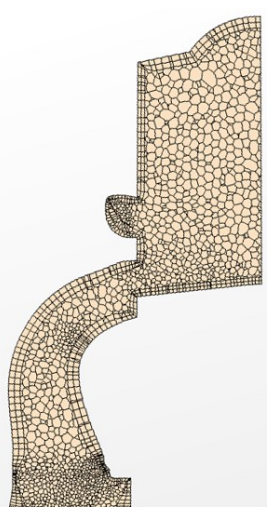

(a)

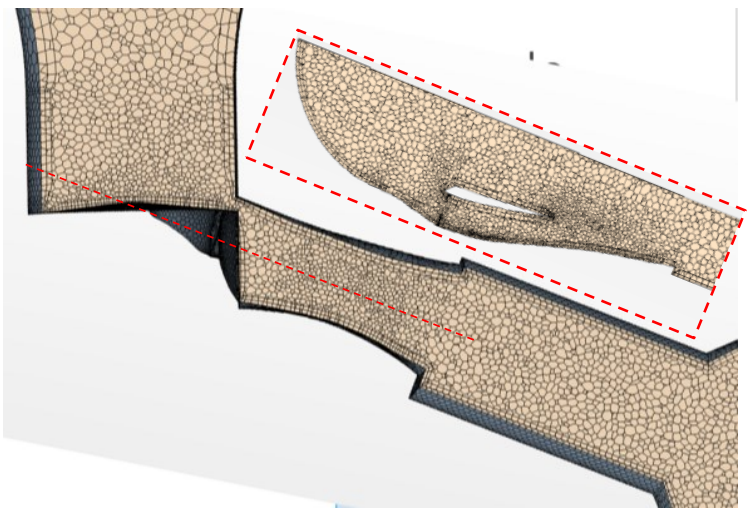

(b)

Fig. 4. Details of the polyhedral grid: cylinder mid-plane of the CFD-C model at piston position near BC (a); symmetry plane of the CFD-B model at piston position near exhaust opening (b), and exhaust mean plane at piston position close to $\mathrm{BC}$ (b-particular). 
A grid sensitivity study was performed on the CFD-A and -B models to determine the optimum grid density for the final CFD-C model (see the following sub-section). The grid density was varied by changing the base size of the mesh without modifying the prism layer to maintain the wall $\mathrm{y}^{+}$higher than 12 in all the computations.

\subsection{Validation of the basic CFD model}

The dependency of the results on the grid density was assessed for models CFD-A and CFD$\mathrm{B}$ in terms of global (mass flow rate across the domain) and local (velocity distribution at the cylinder ports) quantities. Grid densities in the range of approximately $10 \mathrm{k}$ to $1000 \mathrm{k}$ cells in the region including the cylinder and the manifolds were explored. Figures 5(a) and (b) summarise the results obtained for the CFD-B model.

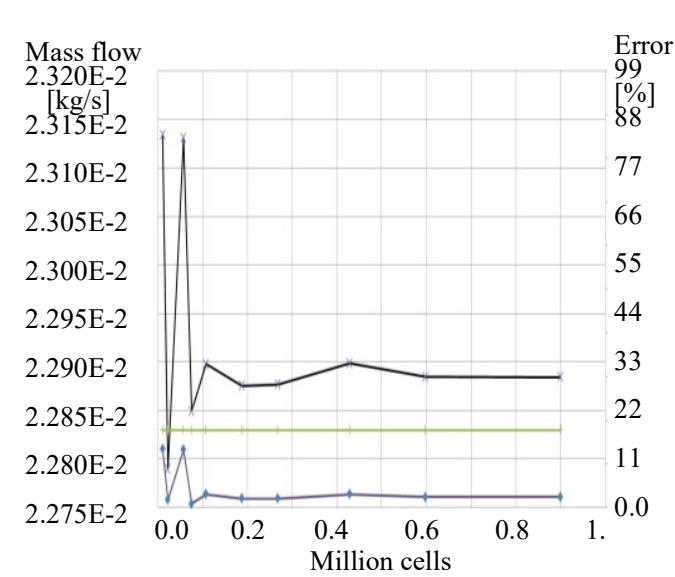

(a)

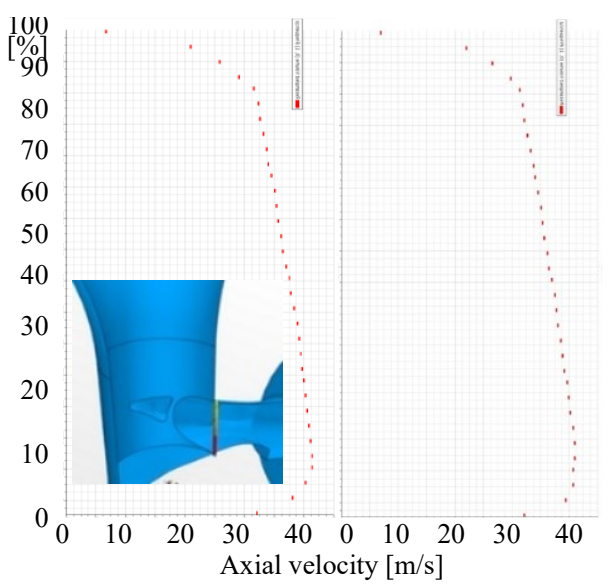

(b)

Fig. 5. Calculated mass flow rate (black), measured mass flow rate (green) and percentage error (blue) at different cell numbers (a); axial velocity distribution at the sensor line placed in the exhaust port predicted by the 100k (left) and 900k (right) cells computations, respectively (b).

The final grid for the CFD-C model contained approximately $100 \mathrm{k}$ cells. This grid density allowed predictions of the flow field in tests $\mathrm{A}$ and $\mathrm{B}$ no more dependent on the grid density.

Figure 6 compares the experimental $C_{f}$ curves to the CFD predictions. Noticeable differences (up to 30\%) exist between the CFD and the experimental results at very small port openings (piston position lower than $4 \mathrm{~mm}$ ), especially for case A. These discrepancies can be mostly explained by the uncertainty in the relative position between the piston and ports (due to the concurring actions of uncertainty in the actual port geometry - e.g. rounded corners - and leakage across the L-ring sealing). This is amplified when the area of the port opening is very small and the mass flow rate is measured in terms of $C_{f}$ (e.g. towards the port opening, a $0.2 \mathrm{~mm}$ position error leads to an error in $C_{f}$ of approximately 0.5$)$. However, in the $C_{f}$ range corresponding to half of the port opening period around $\mathrm{BC}$ (see the red dashed regions), the CFD-B model exhibits a strong prediction capability - Fig.6(a) - as does CFD$\mathrm{C}$, which is important for the application of the proposed design approach - Fig. 6(c). 


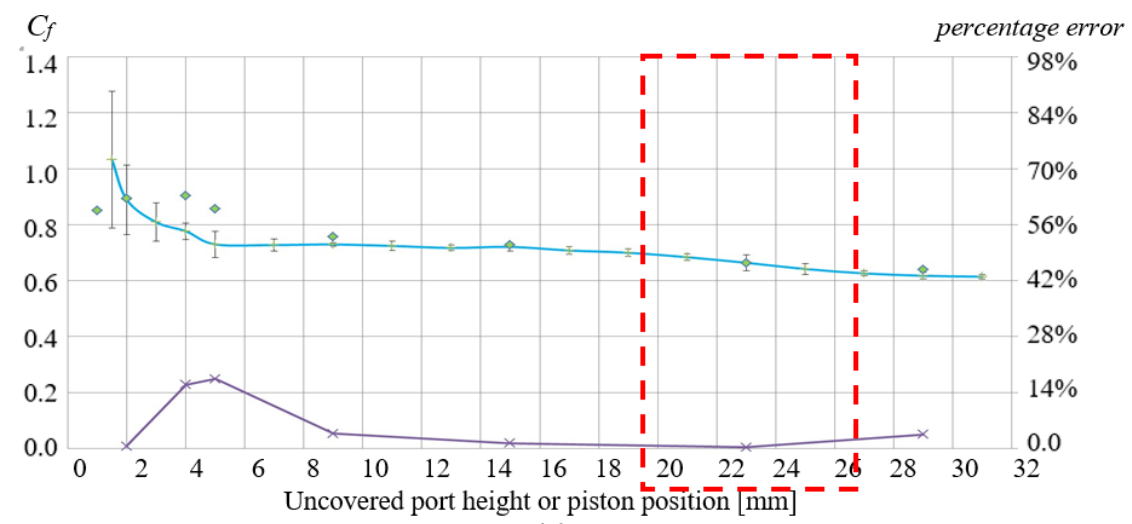

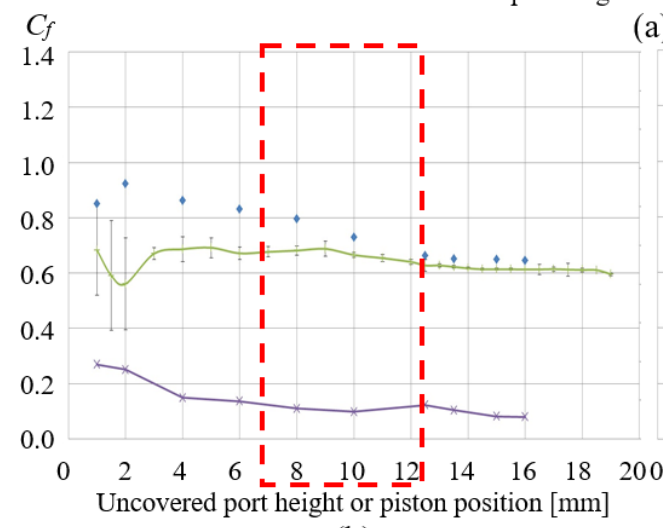

(b) (a)

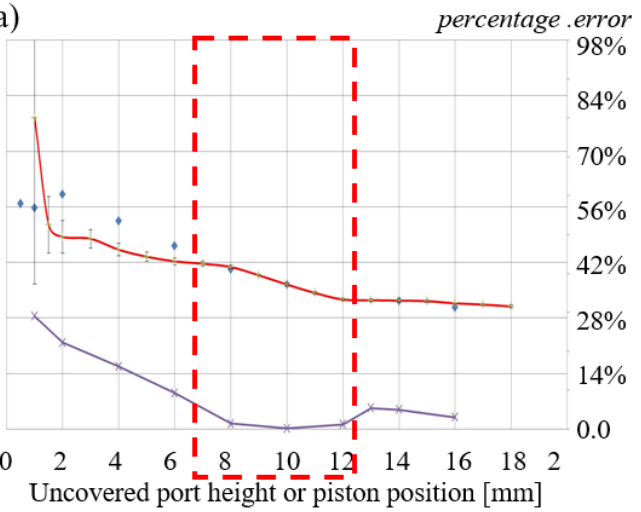

(c)

Fig. 6. Experimental $C_{f}$ (continuous lines), numerical predictions (markers) and percentage error (purple lines) at different piston positions for CFD-B (a), CFD-A (b), and CFD-C (c) models. Error bars show the $95 \%$ confidence level according to the Student distribution, Coloured areas show the ranges of effective areas available from $25 \%$ to $75 \%$ of the ports opening duration.

\section{Application of the method to an FIA-KF2 racing engine}

The goal of the design approach is a performance gain of the Maxter XF racing engine. The results of each step of the approach previously described are summarised in Fig.7. In Step I (left column in Fig.7), the CFD-C model has been applied to the baseline engine geometry, and steady-state calculations have been performed at three piston positions. The top frame compares the axial velocity contours (Jante plot) on the plane at $29 \mathrm{~mm}$ from BC, obtained from calculations with the piston at BC (top) and at $4 \mathrm{~mm}$ transfer ports opening (bottom). The Jante criterion [12] predicts short-circuit of the charge. The contour plot shows that the central part of the upward directed scavenging flow develops well inside the exhaust-side half cylinder (see the zero-velocity red dotted line). The comparison between the flow fields at different piston positions confirms that the most critical scenario occurs when the piston is at $\mathrm{BC}$. The velocity vector analysis is therefore presented only for this case. The middle and bottom frames show three major drawbacks of the baseline design: (i) most of the primary port flow bends towards the exhaust without scavenging the cylinder, (ii) the auxiliary port flow direction is oriented directly towards the exhaust, and (iii) both flows exiting the primary and auxiliary ports are coplanar and almost perpendicular to the cylinder axis so that the latter compels the former towards the exhaust. 

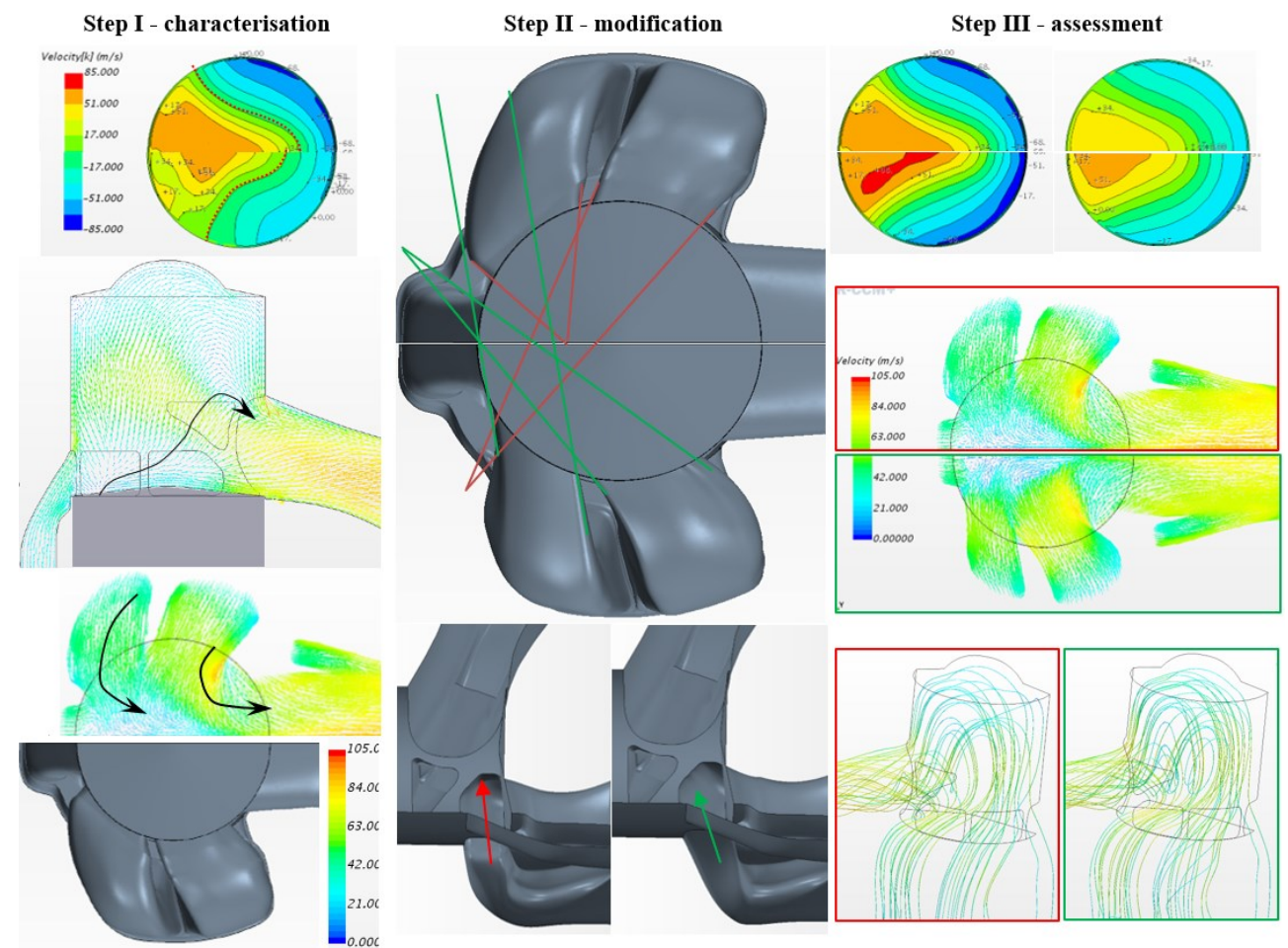

Fig. 7. Step I (left column): Jante plot at $29 \mathrm{~mm}$ from BC and piston at BC (top-top) and at $4 \mathrm{~mm}$ transfer port opening (top-bottom), velocity vectors in the cylinder symmetry plane (middle), and in a plane normal to cylinder axis at $6 \mathrm{~mm}$ from BC (bottom). Step II (middle column): top view (top) and lateral view (bottom) of the baseline (original features are tracked in red) and the modified (modified features are tracked in green) transfer ports geometries. Step III (right column): Jante plot at $29 \mathrm{~mm}$ (top-left) and $42 \mathrm{~mm}$ (top-right) from BC for the baseline (top) and modified (bottom) geometries, velocity vectors in a plane normal to cylinder axis at $6 \mathrm{~mm}$ from $\mathrm{BC}$ for the baseline (middle-top) and modified (middle-bottom) geometries, in-cylinder streamlines for the baseline (bottom- left) and modified (bottom-right) geometries.

In accordance with [13], three design modifications were conceived in Step II and illustrated in the middle column of Fig.7, where the original and modified geometrical features are tracked in red and green, respectively. In particular, (i) the angle between the primary port duct and cylinder symmetry plane was reduced to direct the flow exiting the primary ports towards the central scavenging port in the cylinder back-side; (ii) the axis of the auxiliary port duct was rotated away from the exhaust axis and directed toward the cylinder back-side, so that the axes of the two opposite auxiliary ports were roughly aligned; (iii) the angle between the auxiliary ports and the cylinder axes was reduced, so that the flow exiting from those ports easily enters in the scavenging loop without blocking the flow from the primary ports.

In Step III, the steady-state prediction of the scavenging flow in the modified geometry with the piston fixed at BC was compared to the CFD results from Step I. The top frame of the right-column in Fig.7 compares the axial velocity contours at $29 \mathrm{~mm}$ (left) and $42 \mathrm{~mm}$ (right) from $\mathrm{BC}$ for the baseline (top) and the modified (bottom) designs. Further improvements are possible. However, the increased upward velocities in the core of the back half of the cylinder demonstrate that the scavenging loop was strengthened. The comparative analysis of the vector plots in the plane at $6 \mathrm{~mm}$ from BC and the streamlines plots are shown in the middle and bottom frames of the right-column in Fig. 7 (refer to the red and green 
bordered plots for the baseline and modified designs, respectively). The design modifications introduced in Step II succeeded in reducing the short-circuit of the fresh charge.

As a final task, both the baseline and the modified CFD-C models were upgraded with the inclusion of two passive scalars and restarted in transient mode, to simulate the fresh charge and the exhaust gas flows, respectively. The time step was set to the time required for $1^{\circ}$ crank angle rotation at the maximum engine speed. As initial conditions, a $100 \%$ concentration of the fresh-charge scalar was fixed in the inlet region up to the cylinder ports, whereas only the exhaust-gas scalar was placed in the cylinder and exhaust regions. Both simulations were stopped at delivery ratios $\Lambda>1.6$.

Figure 8 shows the scavenging efficiency $\eta_{s c}$ (a) and the purity of the charge $\beta$ (b) as a function of $\Lambda$. It is apparent from Fig. 8(a) that, for $\Lambda>0.5$, the higher the delivery ratio the higher the $\eta_{s c}$ improvement obtained by the modified geometry (red curve). The purity of the charge should be equal to $\eta_{s c}$ if no short-circuit occurs and the scavenging process develops in accordance with the perfect mixing model. As confirmation of severe short-circuit occurrence, the comparison between Figs. 8(a) and (b) shows that the baseline design (blue curve) features a higher $\beta$ than $\eta_{s c}$ in the range $0.35<\Lambda<1$ (red dotted area). In contrast, the modified design (red curve) features a $\eta_{s c}$ higher than $\beta$ in the entire $\Lambda$ range.

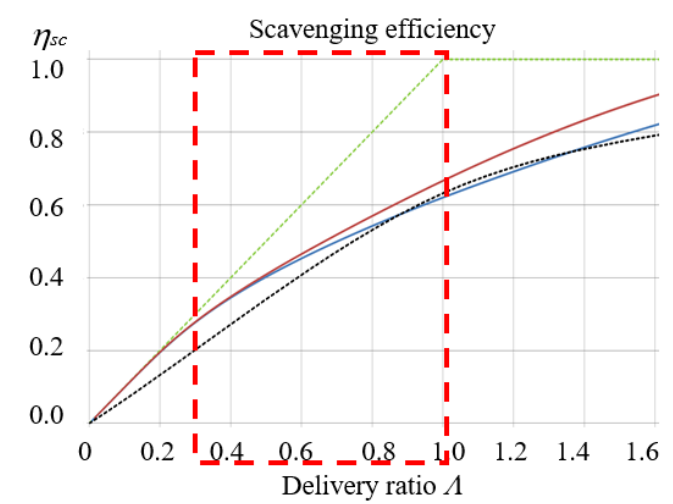

(a)

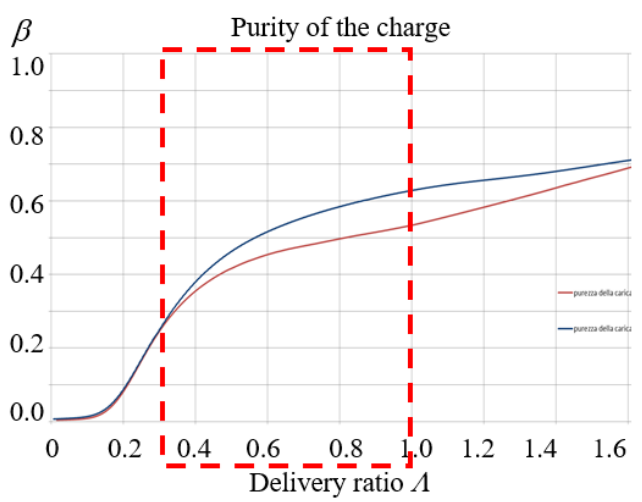

(b)

Fig. 8. Scavenging efficiency (a) and purity of the charge (b) as a function of the delivery ratio for the baseline (blue) and improved design (red) (perfect displacement and perfect mixing model are reported as green and black lines, respectively).

\subsection{Quantification of the performance improvement}

The plot of trapping efficiency $\eta_{r t}$ in Fig. 9(a) allows for the estimation of the increase in output power expected for the improved design by using eq.(1). For example, the engine output increase is approximately $2.4 \%$ if $\eta_{t r}$ is kept equal to $\eta_{r t}$ obtained at the computation time in which the baseline design reaches $\Lambda^{\text {tot }}=1$. In this case, the power increase is partially hindered by a $\sim 6.5 \%$ reduction of $\Lambda^{\text {tot }}$ due to a decrease in the discharge flow coefficients of the transfer ports. The gain in engine output reaches $4 \%$ if the two designs are compared at $\Lambda^{\text {tot }}=1.2$ (i.e., at a common value of the delivery ratio, which is quite usual for small twostroke racing engines [13]). Finally, Fig. 9(b) shows the time evolution of the scavenging process as modelled by the unsteady basic CFD-C model of the baseline (top) and improved (bottom) designs. 


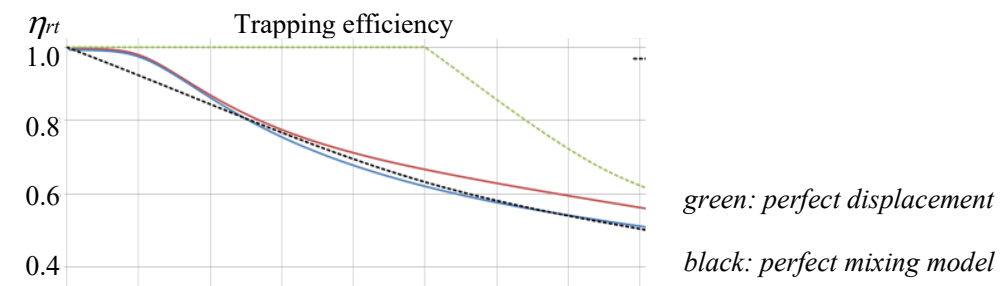

0.2

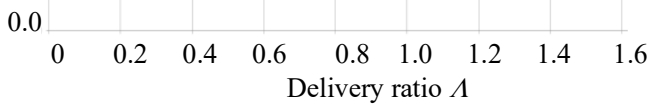

(a)
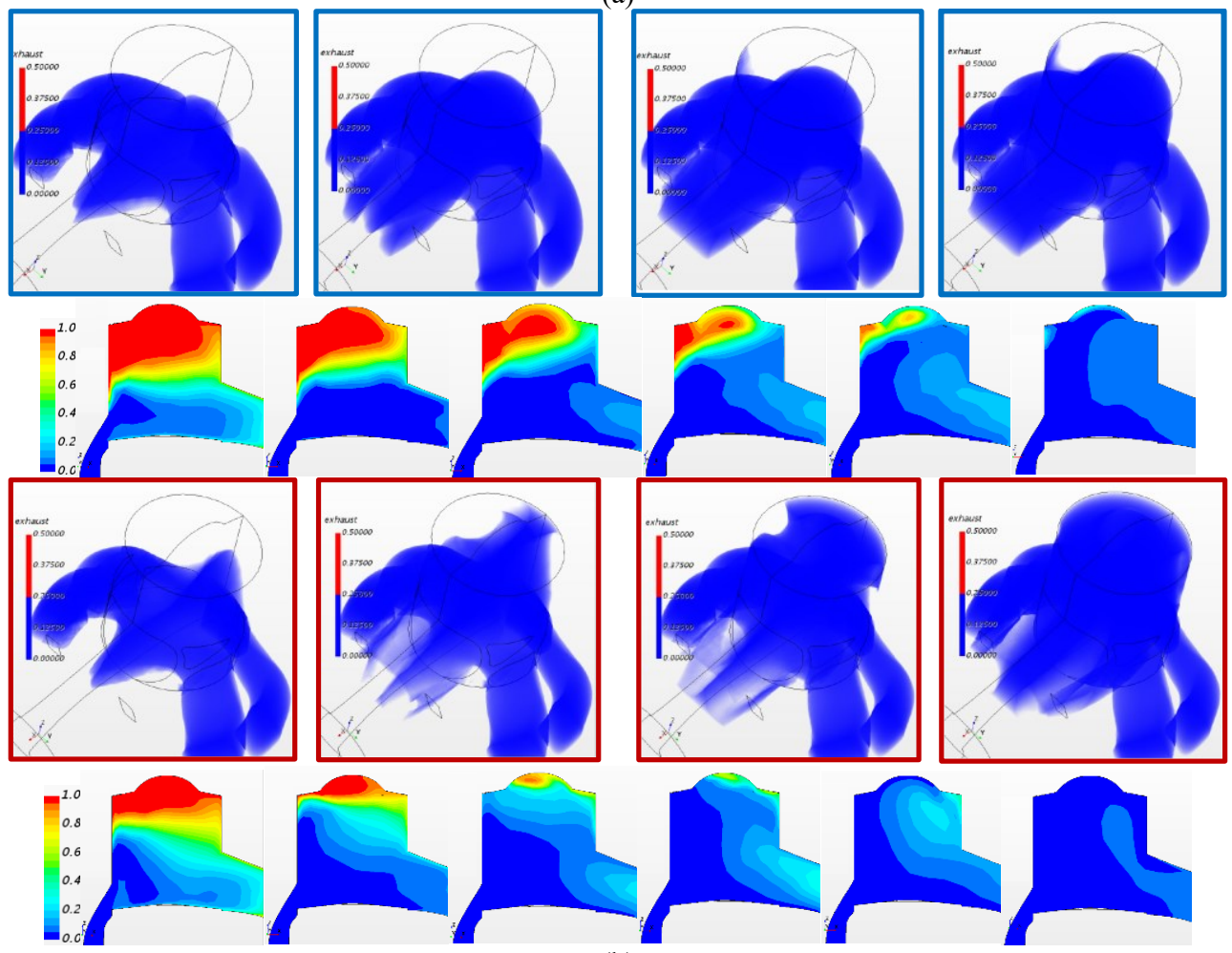

(b)

Fig. 9. Trapping efficiency against delivery ratio $\Lambda$ for the baseline (blue) and improved design (red) (a) and evolution of the scavenging process (from left to right) for the baseline (top) and improved design (bottom) (b).

\section{Summary}

The practical design approach to improve the mean effective pressure of a five-port loopscavenged two-stroke race engine compliant with the KF2 FIA homologation through geometry modifications to the transfer ports and manifolds was formalised in three logical steps. Only a basic CFD model validated by steady-state discharge flow tests is needed. In particular, Step I is aimed at characterising the scavenging process of the baseline engine 
design with a steady-state CFD model of the entire block-cylinder assembly from the crankcase outlet to the first part of the exhaust pipe. In Step II, the analysis of the steady-state results based on consolidated methods and design guidelines available in the literature suggests geometry modifications aimed at improving the gas exchange process. Step III compares the steady-state CFD of the baseline and the improved design to check if the shortcomings of the original design have been reduced and if additional improvements are possible. Finally, a switch of the CFD models of the baseline and improved designs in transient mode helps estimate the increase in the power output expected from the design modifications.

The application of the suggested design approach revealed the following conclusions:

i. Although capable of high performance, the baseline engine featured noticeable short-circuit of the charge.

ii. The analysis provided in the practical approach indicates that the short-circuit of the charge is due to the direction and relative orientation of the primary and auxiliary transfer ports.

iii. Design modifications that slightly reduce the discharge flow coefficients of the transfer ports should allow an increase of the indicated mean effective pressure in the range from $2.4 \%$ to $4 \%$.

iv. According to the design approach, further improvements are possible.

The basic CFD model, having no more than 100k polyhedral cells, compared to the experimental data allows for accurate steady-state flow predictions and, in particular, within the limitations discussed in the paper, can effectively support the rapid and cost-effective design approach presented here to improve loop-scavenged crankcase-compression engines.

\section{Acknowledgments}

The authors gratefully acknowledge Stefano Barison and Marco Calore from HP RACE Snc for their precious technical support.

\section{References}

1. J. B. Heywood and E. Sher, Two-Stroke Cycle Engine: It's Development, Operation and Design (SAE International and Taylor\&Francis, New York, NY, 1999).

2. S. Sturm, S. Schmidt, and R. Kirchberger, SAE Technical Paper 2018-32-0041 (2018).

3. E. Mattarelli, C. Rinaldini, and T. Savioli, SAE Technical Paper 2016-01-0610, (2016).

4. E. Sher, Israel J. Technol., 20, 127-132 (1982).

5. E. Hashimoto, T. Tottori, and S. Terata, SAE Technical Paper 850182, (1985).

6. M. Garg, D. Kumar, M. Syed, and S. Nageswara, SAE Technical Paper 2015-32-0702, (2015).

7. Y. lkeda, M. Hikosaka, and T. Nakajima, SAE Technical Paper 910670, (1991).

8. T. D. Fansler and D. T. French, SAE Technical Paper 920417, (1992).

9. Z. Cao, T. Wang, K. Sun, L. Cui, et al., SAE Technical Paper 2017-01-2201, (2017).

10. J. Galindo, J. V. Pastor, J. R. Serrano, J. M. Pastor, and C. Gaia, SAE Technical Paper 2001-01-3233, (2001).

11. B. Fleck, R. Fleck, R. Kee, X. Hu, et al., SAE Technical Paper 2006-32-0061, (2006).

12. A. Jante, SAE Technical Paper 680468 (1968).

13. G. P. Blair. Design and simulation of two-stroke engines (SAE International, Warrendale PA, 1996).

14. G. P. Blair and R. G. Kenny, SAE Technical Paper 800038, (1980). 
15. R. Fleck and A. Cartwright, SAE Technical Paper 96253, 1996.

16. A. Ferro, The Engineers' Digest, 19, 512-522, (1958).

17. N. R. McKinley, R. Fleck and N. R. Kenny, SAE Technical Paper 921694, (1992).

18. N. R. McKinley, N. R. Kenny and R. Fleck, SAE Technical Paper 940399, (1994). 